\title{
CONSILIUM
}

Berkala Kajian Konseling Dan Ilmu Keagamaan

Avalaible at http://jurnal.uinsu.ac.id/index.php/consilium

ISSN : 2338-0608 (Print) | ISSN : 2654-878X (Online)

\section{Upaya Pencegahan Perilaku Konsumtif Melalui Layanan Informasi Menggunakan Teknik Audio Visual}

\section{Sri Ngayomi Yudha Wastuti ${ }^{1}$, Amir Husin Pangaribuan ${ }^{2}$}

${ }^{1}$ Program Studi Bimbingan Konseling, Fakultas Keguruan dan Ilmu Pendidikan,

Universitas Muhammadiyah Sumatera Utara.

2Madrasah Aliyah Negeri 1 Medan

Korespondensi: yomiyudha@gmail.com

\begin{abstract}
This research is motivated by the development of globalization, which has an extraordinary impact on adolescents. Adolescence is a period where they want to be accepted by their existence and recognized by their existence so that they do everything to fulfill their desires. Adolescence is the process of finding identity, so that makes them more easily influenced and carried away by their environment. The need to be accepted and be the same as other people causes teens to follow various attributes that are popular. One way is to behave consumptively. The formation of consumptive behavior in human beings can be influenced by two factors originating from within the individual (internal) and from outside the individual (external). This study was included in the Quasi Experiment with one group design; the population in this study were MAN 1 Medan students. The sample is class X students of 25 people selected by using purposive sampling technique. The instrument used was a questionnaire with a Likert scale model. The validity test of the research instrument was through the content validity test by several experts and was also carried out using Product Moment Correlation with the mean correlation coefficient of 0.656 and the reliability test using the Cronbach Alpha formula with $r 0.972$.
\end{abstract}

Keywords: Consumptive Behavior, Information Services, Audio-Visual Techniques

\section{PENDAHULUAN}

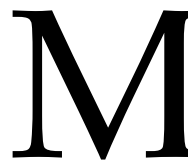

asa remaja merupakan fase perkembangan yang sangat mencolok baik secara fisik, psikologis, dan sosial serta moral. Menurut Hurlock (1994:208) ciri-ciri masa remaja adalah masa mencari identitas, dimana seorang remaja mencari jati dirinya. Pada fase ini seorang remaja mulai mendambakan identitas diri dan tidak puas lagi dengan menjadi sama dengan teman-teman sebayanya yang lain, sehingga hal ini membuat remaja berusaha menampilkan diri mereka agar bisa menarik perhatian masyarakan lainnya. 
Di era globalisasi yang semakin mempermudah semua kegiatan dan aktivitas manusia membuat banyak individu menjadi lupa dan sulit untuk mengontrol keinginannya. Hal ini sering disebut sebagai perilaku konsumtif. Perilaku konsumtif dapat dijelaskan sebagai kecenderungan manusia atau individu untuk melakukan konsumsi tanpa adanya batasan, membeli sesuatu barang yang tidak pernah direncanakan atau tidak dibutuhkan dalam kehidupan secara berlebihan (Chita, David, \& Pali, 2015). Terbentuknya perilaku konsumtif pada dirimanusia dapat dipengaruhi oleh dua faktor yang berasal dari dalam diri individu (internal) dan dari luar diri individu (eksternal) (Chita et al., 2015; Nurhaini, 2018). Seiring perkembangannya zaman, faktor utama yang dapat mempengaruhi perilaku konsumtif pada remaja adalah perkembangan teknologi yang semakin pesat. Kemudahan yang diberikan oleh perkembangan teknologi khususnya internet membuat pergeseran gaya hidup remaja serta kebutuhan hidup manusia yang lebih mudah, praktis, dan cepat (Putri, 2014).

Perilaku konsumtif sendiri tidak hanya terjadi pada orang dewasa yang sudah memiliki penghasilan sendiri, melainkan juga lebih banyak terjadi pada remaja yang masih berada pada masa transisi atau duduk di bangku SMA kisaran usia 15-19 tahun (Chita et al., 2015). Hal ini terjadi dikarenakan pada masa remaja merupakan fase dimana individu masih memulai untuk mencari identitas diri, sehingga hal ini mudah untuk terpengaruh oleh berbagai hal-hal disekitar yang membuat diri mereka penasaran (Sartika \& Yandri, 2019). Salah satu hal yang paling berpengaruh dalam penemuan identitas remaja adalah kemampuan sosial individu itu sendiri dalam hal ini sering disebut sebagai konformitas teman sebaya (Akelaitis, 2015).

Hasil penelitian yang dilakukan pada remaja bahwa perilaku konsumtif dipengaruhi oleh konsep diri dan konformitas teman sebaya. Remaja yang memiliki konsep diri yang rendah maka dirinya akan lebih mudah terpengaruh oleh teman-temannya untuk menimbulkan perilaku konsumtif pada dirinya. Terlihat dari hasil penelitian bahwa konsep diri dan konformitas menyumbangkan 30,4\% terhadap perilaku konsumtif, yang berarti 69,6\% dipengaruhi oleh variabel-variabel lainnya (Suminar \& Meiyuntari, 2015).

Dari hasil riset Priceza yang dikutip dari artikel Marketeers.com, sejak 2015 hingga 2017 kota Bandung merupakan salah satu dari 5 kota besar di Indonesia dengan tingkat pembelanjaan online yang aktif terbanyak dan tersering. Hal ini diperkuat dengan hasil penelitian Oktafikasari, et al. (2017) 
bahwa remaja yang memiliki gaya hidup kearah hedonisme dan kecenderungan konsumtif memiliki nilai konformitas yang tinggi terhadap teman sebayanya, remaja melakukan kegiatan-kegiatan konsumtif dan lebih cenderung mengikuti apapun yang dibeli oleh teman-temannya meski hal tersebut tak penting dalam kehidupannya (Yudasella \& Krisnawati, 2019).

Berdasarkan hasil penelitian yang dilakukan oleh Mulia Sartika, bahwa penurunan tingkat konformitas teman sebaya dalam perilaku konsumtif berhasil dengan dilakukannya layanan bimbingan kelompok sebesar 17,19\% (Sartika \& Yandri, 2019). Hal ini dapat disimpulkan bahwa dalam konformitas teman sebaya adalah faktor eksternal terkuat dalam terbentuknya perilaku konsumtif pada remaja maka dari itu dalam pelayanan bimbingan kelompok diutamakan untuk menurunkan tingkat konformitas teman sebaya terlebih dahulu agar saat menurunkan perilaku konsumtif tidak ada lagi faktor-faktor lain yang mampu menghambat keberhasilan pemberian layanan.

Tambunan (dalam www.e-psikologi.com/remaja) menjelaskan pola hidup yang konsumtif cenderung dilakukan pada usia remaja oleh karena itu bagi responden remaja adalah salah satu pasar untuk menjual paling berpotensi adalah usia remaja karena tingkat konsumsi yang juga mudah dipengaruhi. Di samping itu biasanya remaja lebih mudah untuk terbujuk rayuan iklan, konformitas teman sebaya, dan cenderung boros dalam segi keuangan (Hartati, 2011).

Perilaku konsumtif merupakan perilaku individu yang ditujukan untuk mengkonsumsi tiada batas terhadap barang dan jasa yang kurang atautidak diperlukan, hanya berdasarkan keinginan semata tanpa pertimbangan yang rasional (Wienaldi, 2017). Para pelaku konsumtif berperilaku demikian dikarenakan adanya rasa kepuasan yang dirasakan jika bisa memenuhi semua hasrat yang diinginkan oleh dirinya dan juga peningkatan harga dirinya dalam kelompok, dan kesenangan semata yang sering kali tidak di imbangai dengan kemampuan materi yang dimilikinya (Hartati, 2011).

Menurut simamora (2003) faktor-faktor yang mempengaruhi perilaku konsumen adalah; terbentuknya perilaku konsumtif tidak terjadi dengan sendirinya. Ada bebrapa faktor yang berpotensi menjadi penyebab terjadinya perilaku konsumtif pada diri individu. Adapun faktor-faktor yang mempengaruhi terjadinya perilaku konsumtif adalah sebagai berikut: (1) Faktor kebudayaan; (2) Faktor Sosial; (3) Faktor Pribadi; dan faktor Psikologis. 
Sedangkan menurut Awaliya, dkk (2008) menjelaskan bahwa faktor-faktor yang mempengaruhi kegiatan konsumsi sebagai berikut: (1) Penghasilan; (2) Adat istiadat; (3) Mode; (4) Selera; dan (5) Iklan.

Perilaku konsumtif ini dapat terus terjalin di dalam gaya hidup sekelompok remaja, dalam hal ini remaja mampu berkembang menjadi orangorang dengan gaya hidup konsumtif dan hedonis (Triyaningsih, 2011). Dalam hal ini sebenarnya tidak terjadi masalah jika pencapaian tingkat keuangan itu dilakukan dalam hal yang baik, namun yang menjadi masalah jika pencapaian tingkat keuangan didapatkan dari hal yang negative karena keinginan yang lebih tinggi dibandingkan kemampuan ekonomi individu (Yudasella \& Krisnawati, 2019).

Selain melaksanakan layanan bimbingan kelompok, salah satu layanan konseling lainnya yang dapat mencegah terjadinya perilaku konsumtif adalah pemberian layanan informasi kepada remaja. Konselor atau Guru BK diminta untuk menyampaikan beberapa materi yang bisa memberikan pemahaman kepada siswa bahwa perilaku konsumtif dapat membahayakan gaya hidup remaja masa kini. Layanan informasi merupakan layanan untuk membekali para peserta didik dengan pengetahuan tentang data dan fakta di bidang materi yang ingin diberikan, agar siswa atau peserta didik mampu merencanakan kehidupannya sendiri (winkel \& Hastuti, 2006). Prayitno (2012) menjelaskan bahwa layanan informasi merupakan layanan yang mampu mengisi kekurangan individu akan beberapa informasi yang dibutuhkan oleh individu yang bersangkutan.

Dapat disimpulkan layanan informasi merupakan layanan yang berusaha membekali individu dengan pengetahuan tentang data dan fakta di bidang pendidikan sekolah, bidang pekerjaan, dan bidang perkembangan pribadi sosial. informasi tersebut selanjutnya diolah dan digunakan oleh individu untuk lebih mudah dalam membuat perencanaan dan pengambilan keputusan untuk kehidupan dirinya kedepannya (Rambe, Mudjiran, \& Marjohan, 2017).

Pelaksanaan layanan informasi telah dilakukan oleh guru BK atau konselor yang ada di sekolah, namun layanan informasi yang digunakan belum berjalan secara optimal. Hal ini banyak membuat siswa yang mengikuti layanan informasi di kelas menjadi mudah bosan dikarenakan teknik atau metode yang digunakan oleh guru BK atau konselor hanyalah ceramah saja. Oleh karena itu, 
pelaksanaan layanan informasi dapat dioptimalkan menggunakan tambahan metode yaitu metode media audio visual (Natalia, Firman, \& Daharnis, 2015). Berdasarkan hal tersebut, perlu diteliti layanan informasi untuk mencegah perilaku konsumtif pada siswa menggunakan metode audio visual yang dapat menarik perhatian siswa saat mengikuti layanan informasi di kelas.

Penelitian ini secara umum untuk menguji efektivitas layanan informasi dengan menggunakan media audio visual dalam mencegah perilaku konsumtif pada siswa. Sedangkan tujuan khusus untuk menguji: (1) perbedaan pemahaman siswa kelompok eksperimen terhadap perilaku konsumtif sebelum dan sesudah mengikuti layanan informasi dengan media audio visual.

\section{METODE PENELITIAN}

Penelitian ini termasuk dalam Quasi Eksperimen dengan desain one group design, populasi dalam penelitian ini adalah siswa MAN 1 Medan. Sampel adalah siswa kelas X Berjumlah 25 orang yang dipilih dengan menggunakan teknik purposive sampling. Instrumen yang digunakan berupa angket dengan model skala likert. Uji validitas instrumen penelitian melalui uji validitas isi oleh beberapa ahli dan juga dilakukan menggunakan product Moment Corelation dengan mean koefisieankorelasi 0,656 dan uji reliabilitas menggunakan rumus Alpha Cronbach dengan r 0,972.

Data yang terkumpul dianalisis dengan cara menghitung skor rata-rata perilaku konsumtif siswa. Setelah deskripsi data tersebut, dihitung rentangan data atau interval. Agus Irianto (2010) menjelaskan untuk menghitung rentangan data atau interval daoat dilakukan dengan menghitung data tertinggi dikurang data terendah lalu dibagi jumlah kelas, sehingga diperoleh kategori yang diklasifikasi dengan kriteria pada tabel berikut.

Tabel 1. Kategorisasi Perilaku Konsumtif Siswa

\begin{tabular}{cc}
\hline Skor & Kategori \\
\hline $190-161$ & Sangat Tinggi \\
\hline $160-131$ & Tinggi \\
\hline $130-101$ & Sedang \\
\hline $100-71$ & Rendah \\
\hline $10-41$ & Sangat Rendah
\end{tabular}

Selanjutnya data yang diperoleh dianalisis dengan menggunakan uji Wilcoxon Signed Ranks Test dan Kolmogrov Smirnov 2 Independent Samples. 


\section{HASIL PENELITIAN DAN PEMBAHASAN}

\section{Hasil}

Data penelitian yang diperoleh pada kelompok eksperimen sebelum dan sesudah diberikan perlakuan terdapat pada tabel berikut.

Tabel 2. Perbandingan Siswa kelompok Eksperimen Pre-test-Posttest terhadap Perilaku Konsumtif.

\begin{tabular}{|c|c|c|c|c|}
\hline \multirow[t]{2}{*}{ Kode Siswa } & \multicolumn{2}{|c|}{ Pretest } & \multicolumn{2}{|c|}{ Posttest } \\
\hline & Skor & Kategori & Skor & Kategori \\
\hline E1 & 188 & ST & 143 & $\mathrm{~T}$ \\
\hline E2 & 180 & ST & 122 & S \\
\hline E3 & 172 & ST & 105 & $S$ \\
\hline E4 & 180 & ST & 126 & $S$ \\
\hline E5 & 168 & ST & 110 & $S$ \\
\hline E6 & 160 & $\mathrm{~T}$ & 93 & $\mathrm{R}$ \\
\hline E7 & 168 & ST & 77 & $\mathrm{R}$ \\
\hline E8 & 172 & ST & 82 & $\mathrm{R}$ \\
\hline E9 & 141 & $\mathrm{~T}$ & 100 & $\mathrm{R}$ \\
\hline E10 & 145 & $\mathrm{~T}$ & 92 & $\mathrm{R}$ \\
\hline E11 & 143 & $\mathrm{~T}$ & 80 & $\mathrm{R}$ \\
\hline E12 & 138 & $\mathrm{~T}$ & 75 & $\mathrm{R}$ \\
\hline E13 & 135 & $\mathrm{~T}$ & 91 & $\mathrm{R}$ \\
\hline E14 & 180 & ST & 88 & $\mathrm{R}$ \\
\hline E15 & 100 & $\mathrm{R}$ & 98 & $\mathrm{R}$ \\
\hline E16 & 132 & $\mathrm{~T}$ & 84 & $\mathrm{R}$ \\
\hline E17 & 103 & $S$ & 72 & $\mathrm{R}$ \\
\hline E18 & 101 & $S$ & 90 & $\mathrm{R}$ \\
\hline E19 & 123 & $S$ & 92 & $\mathrm{R}$ \\
\hline E20 & 134 & $\mathrm{~T}$ & 85 & $\mathrm{R}$ \\
\hline E21 & 133 & $\mathrm{~T}$ & 73 & $\mathrm{R}$ \\
\hline E22 & 135 & $\mathrm{~T}$ & 72 & $\mathrm{R}$ \\
\hline E23 & 144 & $\mathrm{~T}$ & 69 & SR \\
\hline E24 & 106 & $S$ & 54 & SR \\
\hline E25 & 98 & $\mathrm{R}$ & 50 & SR \\
\hline Rata-rata & 143,16 & $\mathrm{~T}$ & 88,92 & $\mathrm{R}$ \\
\hline
\end{tabular}

Berdasarkan tabel di atas terlihat bahwa sikap siswa kelompok eksperimen terhadap perilaku konsumtif menurung secara signifikan sesudah diberikan perlakuan layanan informasi dengan media audio visual. 


\section{Pembahasan}

Berdasarkan hasil uji hipotesis yang berbunyi terdapat perbedaan signifikan pemahaman siswa kelompok eksperimen terhadap perilaku konsumtif sebelum dan sesudah mengikuti layanan informasi dengan media audio visual. Pengujian dilakukan dengan uji Wilcoxon signed Ranks Test.

Hasil penelitian yang diperoleh menunjukkan bahwa skor sikap siswa terhadap perilaku konsumtif mengalami penurunan yang cukup signifikan. Skor total sikap siswa terhadap perilaku konsumtif sebelum diberikan layanan informasi dengan media audio visual rata-rata sebesar 143,16. Selain itu secara rata-rata skor sikap siswa terhadapperilaku konsumtif pada saat pretest berada pada kategori Tinggi.

Sesudah siswa diberikan layanan informasi dengan media audio visual, kondisi sikap siswa terhadap perilaku konsumtif mengalami penurunan yang signifikan. Perolehan skor total posttest dengan nilai rata-rata sebesar 88,92 dan siswa juga berada pada kategori Rendah. Selisih skor nilai rata-rata sebelum dan sesuah diberikan perlakuan adalah sebesar 54,24.

Layanan informasi adalah salah sau jenis layanan yang ada dalam pelayanan bimbinngan dan konseling yang berfungsi mengembangkan pemahaman siswa dan mencegah tingkah laku siswa agar tidak berada dalam nilai yang negative. Dalam pelaksanaan layanan informasi juga dapat dioptimalkan dengan menggunakan metode tambahan dan juga media tambahan (Nikmah, 2014).

Perilaku konsumtif merupakan sebagai kegiatan-kegiatan individu yang secara langsung terlibat dalam mendapatkan dan mempergunakan barang dan jasa, termasuk di dalamnya proses pengambilan keputusan pada persiapan dan penentuan kegiatan-kegiatan tersebut (Nurhaini, 2018).

\section{Kesimpulan}

Berdasarkan hasil penelitian, dapat disimpulkan secara umum bahwa layanan informasi dengan menggunakan media audio visual efektif untuk menurunkan perilaku konsumtif siswa. Sedangkan secara khusus, yaitu:

1. Tingkat perilaku konsumtif siswa di sekolah MAN 1 Medan terkhusus pada siswa kelas $X$ berada pada kategori tinggi. Dimana siswa-siswa dijadikan 
sampel untuk diberikan pelayanan bimbingan dan konseling oleh guru BK atau konselor di sekolah tersebut.

2. Terdapat perbedaan yang signifikan sikap siswa terhadap perilaku konsumtif sebelum dan sesudah diberikan layanan informasi menggunakan media audio visual.

\section{DAFTAR PUSTAKA}

Akelaitis, A. V. (2015). Social Skills Expression of Senior High School Age Students in Physical Education Classes, (14), 232-238. https:/ / doi.org/10.13187/ejced.2015.14.232

Chita, R. C. M., David, L., \& Pali, C. (2015). Hubungan antara Self-Control dengan perilaku Konsumtif Online Shopping Produk Fashion pada Mahasiswa Fakultas Kedokteran Universitas Sam Ratulangi Angkatan 2011, 3(April).

Hartati, F. S. (2011). Upaya Meminimalkan Perilaku Konsumtif Melalui Layanan Konseling Kelompok pada Siswa Kelas VII SMP Negeri 12 Semarang Tahun Ajaran 2010/2011.

Irianto, Agus. 2010. Statistik: Konsep dasar dan Aplikasinya. Jakarta: Predana Media.

Natalia, N., Firman, F., \& Daharnis, D. (2015). Efektivitas Layanan Informasi dengan Menggunakan Media Audio Visual dalam Jurnal Konseling dan Pendidikan. Jurnal Konseling Dan Pendidikan, 3(2), 40-48.

Nikmah, T. (2014). Layanan Informasi Berbantuan Audio Visual untuk Meningkatkan Persepsi Hubungan Remaja yang Sehat Siswa Kelas VIII C SMP 1 Bae Kudus Tahun Ajaran 2013/2014.

Nurhaini, D. (2018). Pengaruh Konsep Diri dan Kontrol Diri dengan Perilaku Konsumtif terhadap Gadget Remaja SMAN 1 Tanah Grogot. Ejournal.psikologi.fisip-Unmul.ac.id, 6(1), 211-223.

Putri, I. W. (2014). Dampak Fast Food Advertising terhadap Perilaku Konsumtif Anak-anak.

Rambe, S. A., Mudjiran, \& Marjohan. (2017). Pengembangan Modul Layanan Informasi untuk Mengembangkan Kontrol Diri dalam Penggunaan Smartphone. Konselor, 6(4), 132-137.

Sartika, M., \& Yandri, H. (2019). Pengaruh Layanan Bimbingan Kelompok terhadap Konformitas Teman Sebaya. Indonesian Journal of Counseling $\mathcal{E}$ Development, 1(1), 9-17. 
Suminar, E., \& Meiyuntari, T. (2015). Konsep Diri, Konformitas dan Perilaku Konsumtif pada Remaja. Jurnal Psikologi Indonesi, 4(2).

Triyaningsih, S. . (2011). Dampak Online Marketing Melalui Facebook terhadap Perilaku Konsumtif Masyarakat, 11(2), 172-177.

Wienaldi, D. (2017). Pengaruh Intensitas Mengakses Tokopedia.com terhadap Perilaku Konsumtif Remaja Perempuan Surabay.

Yudasella, I. F., \& Krisnawati, A. (2019). Pengaruh Literasi Keuangan terhadap Perilaku Konsumtif Siswa Sekolah Menengah Atas di Kota Bandung. Jurnal Mitra Manajemen, 3(6), 674-687. 